\title{
M.Phil. Programs in IT and Computing into New Heights: A Case Study of Srinivas University, Karnataka
}

\author{
P. K. Paul ${ }^{1}$, P. S. Aithal ${ }^{2}$ and K. S. Shivraj ${ }^{3}$ \\ ${ }^{1}$ Raiganj University (RGU), West Bengal, India \\ ${ }^{2}$ Vice-Chancellor, Srinivas University, Karnataka, India \\ ${ }^{3}$ Head, Learning Resource Centre, KL University, Andhra Pradesh, India \\ E-Mail: pkpaul.infotech@gmail.com
}

\begin{abstract}
Computing programs are internationally available at different levels and nomenclatures. The popular levels in this regard are Bachelors and Master's Degree. Internationally the Bachelors programs are commonly available as BS and MS program. Though UK and its follower countries the level and nomenclature are also called and popular as BSc and MSc programs. Worldwide Computing and IT programs are available only in science platform (except few countries that offers Master of Engineering/ Technology program). As far as Research levels are concerned most common are $\mathrm{PhD}$ and M.Phil. Though, among these, $\mathbf{P h D}$ is most common. However, it is worthy to note that M.Phil. Program is not offered and not so much popular in some countries. M.Tech by Research is considered as another program of research level offered to the B.Tech. / BE degree holders and in some cases MSc degree holders. In India, M.Phil. and PhD are available in IT and Computing fields for the science candidates, though engineering post graduate in related fields may also join the program. M.Phil. program in India is offered only at universities. In recent past, the number of private universities has been significantly increased and thus many of them are offer M.Phil. And many of those private universities offer M.Phil.in the field of IT and Computing. The traditional M.Phil. Programs are concentrated on broad areas viz. Computer Science/ Applications. Though, a significant move was undertaken by the Srinivas University, Karnataka for offering M.Phil.in subfields of IT. The paper discusses in detail of M.Phil. Program available in India with a special focus on specialized M.Phil.in Cloud Computing, Big Data Analytics etc. Paper also tries to move into healthy educational policy related work for future potentialities.
\end{abstract}

Keywords: Computer Application, Research Degree, Universities, Indian Education, M.Phil. M.Tech. (Research), M.Phil. in Cloud Computing, M.Phil. in Big Data Analytics

\section{INTRODUCTION}

Research is the prime force for the development in different scale and valuable in almost all the areas and fields. Research degrees thus most important and valuable and as a result, most of the countries provide priorities in producing research degrees with quality [1], [5], [13]. Internally PhD i.e. Doctor of Philosophy is treated as most valuable degree and considered important and recognized. While apart from these few other research degrees are also available internationally these are M.Phil., M.Res. M.Tech. (Research) and some of the Post-Doctoral Degrees viz. Doctor of Science (D.Sc.), Doctor of Literature/ Letters (D.Litt.) etc.

Importantly all these degrees are available in Information Technology and Computing field internationally in many countries. In India, PhD and M.Phil. are common degrees and in Information Technology and Computing as well these degrees are available. Indian higher education segment today many ways depends on the private sectors and a large number of institutions fall under this category. As far as private universities concerned Ph.D... and M.Phil. both are common and many private universities offer M.Phil. Programs in the field of Computing and Information Technology with the nomenclature of Computer Science, Computer Application etc. Though in the field of Computing and IT some of the emerging areas are as follows:
1. Cloud Computing
2. Big Data Analytics
3. Data Science and Management
4. Green Computing
5. Usability Engineering
6. Human Computer Interaction
7. Artificial Intelligence
8. Internet of Things (IoT) etc.

The educational programs in Information Technology and Computing with reference to above not yet offered in most of the countries with Bachelors, Masters Degrees. Though, the above areas of IT are offered as M.Phil. and Ph.D. degrees. It is worthy to mention that such Research Degrees in such areas versus a Bachelors/ Masters in the above is significantly different due to coursework components and skill contents in Bachelors/ Masters [2], [3], [14]. Hence they may be professional in IT organizations while M.Phil. /Ph.D. in such areas only to grab the opportunities in research and academia. Though, a novel model has been designed and started by the Srinivas University by introducing huge coursework and skill content enriched M.Phil.in Cloud Computing/ Big Data Analytics programs [3], [4], [14]. 


\section{OBJECTIVES AND AIM}

The core aim and objective of this conceptual research work include (but not limited to) the following-

1. To learn about the basic educational programs in the field of Information Technology and Computing available worldwide and India.

2. To dig out the research degrees available worldwide and in India in the areas of Information Sciences and Technology.

3. To learn about the common subjects available in the areas of IT and Computing with M.Phil. level.

4. To know about the Private Universities in India with reference to M.Phil. Programs available in India.

5. To learn about the new age professional-skill based M.Phil. Degrees available in India emphasizing Srinivas University, Karnataka.

6. To dig out the possibilities of more specialized M.Phil. Program in different context and views.

\section{METHODS ADOPTED AND SOURCES}

Present work is conceptual in nature and deals with both secondary sources of knowledge and primary sources of knowledge. Initially to gain about the basics of Computing and allied areas review of the literature has been undertaken. Though later on primary souses have been used viz. journals and communications. To reach the core portion of the projected research work web review has been undertaken and here core website of UGC (Government of India) mainly selected and used. The URL https://www.ugc.ac.in/privatuniversity.aspx is considered, analyzed and reported. To learn about the availability of other emerging and new age specialized M.Phil. Program the concerned website is used and analyzed. The study has been conducted in between October, 2017 to November, 2017.

\section{RESEARCH DEGREES IN INDIA}

In India, there are several Research Degrees available and the common one is Ph.D. (Doctor of Philosophy) it is 3 years to 6 years program of study available only in Regular Mode of study (may be full-time or part-time). It is normally offered after Master's degree, and a Ph.D. normally combines Course-work and Research-work [6], [7], [13]. Though due weight is given to the Research work and Course-work is normally deals with Minimum 8 Credit. Though another lower level of Research Degree called M.Phil. (Master of Philosophy) is 1 year to 2 years program and offered in the Regular mode of study. Like Ph.D. the eligibility criteria for the M.Phil.is also same i.e. Master's Degree [8], [9], [14].

An M.Phil. Degree is offered only in the branch of Science, Humanities and Commerce/Management whereas a $\mathrm{PhD}$ degree is additionally also offered in other streams viz. Engineering, Medicine, Dentistry, and Pharmacy. An M.Phil.in India is offered in a different type of universities and their affiliated institutions and colleges.

\section{A. M.Phil.in Private Universities in India}

In India, M.Phil. degree is offered in different types of following universities viz.

1. Central University

2. State University

3. Private University

4. Deemed to be University

Though, apart from these universities some Institutes of National Importance (INI) also offers M.Phil. Programs. In last decade India credited efforts in establishment of private universities and today a large number of universities of such category have been established [10], [11], [16]. As on October, 2017 during the study it is noticed that India hold 279 Private Universities in its bag. Among these Universities 17 are offering M.Phil. Program in IT and Allied field of study. However interestingly as far as number of M.Phil. Programs are concerned, in the IT and field and the number touches 19 (nineteen).

\section{B. M.Phil. in IT and Computing}

The M.Phil. Program in IT and Computing in India is offered in different nomenclatures. As far as Private Universities are concerned following nomenclatures are offered

1. Computer Science

2. Computer Application

3. Information Technology.

It is worthy to note that these above mentioned nomenclatures is offered for the Science post Graduate in related fields viz. MSc-IT/CS/CA or MCA. However if interested an M.Tech. in IT and Computing related fields may also grab the opportunities of M.Phil.in the related fields [12], [15], [17]. This is may also treated as a great opportunity due to non-availability of M.Phil. Degree for the Engineering Post Graduate (M.Tech./ME). The M.Phil. Program is one year based and here the course is divided into two semesters.

\section{M.Phil.: The Super Specialty}

In India Educational Programs and fields are mainly popular in the core subjects. For example, if it is Economics then only MA/M.Sc.-Economics is offered, there is no scope for further study viz. MSc-Health Economics/ Environmental Economics etc. Regarding IT and Computing also emerging subjects are Cloud Computing, Big Data, Advance Networking, Usability Engineering, Human Computer Interaction etc. Internationally these areas are now established as a separate field of study with BSc/MSc program [1], [14], [18]. Students completed a BSc-IT/CS etc. in India normally move for an M.Sc.-IT/CS/MCA rather M.Sc. in Cloud Computing, Big Data, Advanced Networking, Usability Engineering, Human Computer Interaction etc. Practically in academia and students 
community there is very less awareness regarding the availability of MSc/ BSc programs in the field of study. Naturally, those who earned a related MSc/MCA in India normally go for M.Phil.in broad areas such as IT/CS/ Computer Application. There is no awareness and even availability of specialized M.Phil.in the IT and Computing fields. It is important to note that though universities will offer M.Phil.in any of the areas (viz. Networking Technologies), but the concentration will be on research or on a given topic only. Rather knowledge on the field and skills. Though ample opportunity is there regarding skill based and coursework enriched M.Phil. Program. An emerging and new age M.Phil. Program has been started by Srinivas University, Karnataka in India.

\section{M.Phil. \& Srinivas University Focus: Cloud and Big Data}

With identification of the potentiality of Emerging fields and areas, Srinivas University has started two amazing specialization at Masters level. Importantly the degree is offered at M.Phil. Level in which degree holders not only will get a Degree of advance stage but also skilled contents and curricula. Hence instead of MSc one can grab the M.Phil. and additionally can go for the industry or research. This is perhaps the first program as per the study which offers an M.Phil.in latest subject and also industrial opportunity. Two important programs are:

1. M.Phil.- Data Analytics and Cloud Computing

2. M.Phil.-Big Data \& Business Analytics

Both the programs are truly international and available in Regular On-Campus mode of study importantly the program is One year based but to keep more coursework the program is offered in Trimester Pattern in which first two trimester is dedicated on coursework and last one is dedicated to the research work. Moreover the M.Phil. are may be undertaken at the industries or research institutions based on interest of the candidates. Significantly the program is Evening one and thus one can complete while in the job. The Program is offered Three days in a week. The Eligibility for the program is as follows:

1. MCA, M.Tech. (CS/IT/EC), \& M.Sc. (Maths/CS/Electronics, Stat,) degree holders from any UGC recognized University with a minimum of $50 \%$ Marks.

\section{E. Benefits of the Specialized M.Phil. Programs}

The program of M.Phil.in Data Analytics \& Cloud Computing under the College of CIS at the Srinivas University is an emerging specialization in the field of IT. The program has been designed to create ready manpower in the field of Cloud Computing and Big Data as expertise required in this field are enormous. The course contents are designed for taking effective decision maker in big data handling environment and thus theory and practical have been added in most of the papers/ courses. With an M.Phil. Data Analytics and Cloud Computing a postgraduates in IT, Computer Applications, Computer Science or related subjects can complete the program in three trimesters with 12 core subjects and one master industry level project. Table I is depicted the complete requirement for the said M.Phil. Program in details. Moreover the program is also facilitates the postgraduates who want to grow quickly through an advanced area of study in Business Analytics. Business Analytics is most important for every type of organizations and institutions to keep competitive advantage in information explosion and in the age of flood of digital data. The problem of complex Data may be solved by the Business Analytics and thus it is useful in other businesses, government, and scientific agencies.

TABLE I M.PHIL.IN DATA ANALYTICS \& CLOUd COMPUTING FULL STRUCTURE [19]

\begin{tabular}{|c|c|c|c|}
\hline Sl. No. & Courses & Marks & Study Hours \\
\hline \multicolumn{4}{|c|}{ TRIMESTER 1} \\
\hline 1 & Programming using Python (T\&P) & 100 & 40 \\
\hline 2 & $\mathrm{R}$ - Programming Fundamentals (T\&P) & 100 & 40 \\
\hline 3 & Data warehousing and Data Mining ( $\mathrm{T} \& \mathrm{P}$ ) & 100 & 40 \\
\hline 4 & Big Data Technologies & 100 & 40 \\
\hline 5 & Database Systems in Big Data (T \& P) & 100 & 40 \\
\hline 6 & Mini Project & 100 & 40 \\
\hline \multicolumn{4}{|c|}{ TRIMESTER 2} \\
\hline 1 & Hadoop Distributed File Systems (T \& P) & 100 & 40 \\
\hline 2 & Map Reduce (T \& P) & 100 & 40 \\
\hline 3 & Big Data Analytics (T \& P) & 100 & 40 \\
\hline 4 & Data Mining Application with R (T \& P) & 100 & 40 \\
\hline 5 & Marketing \& Social Media Analytics & 100 & 40 \\
\hline 6 & Empirical Research \& Scholarly Publication & 100 & 40 \\
\hline \multicolumn{4}{|c|}{ TRIMESTER 3} \\
\hline 1 & Project & 600 & - \\
\hline
\end{tabular}


According to the Report of McKinsey Global Institute's Big data, the next frontier for innovation, competition, and productivity estimates that by 2018, "the United States alone could face a shortage of 140,000 to 190,000 people with deep analytical skills as well as 1.5 million managers and analysts with the know-how to use the analysis of big data to make effective decisions". Moreover, the McKinsey Global Institute's Big data has reported that the earning opportunity through job \& consultancy work for Business Analytics Experts is 5 to 10 times more than other professions in the society [19], [20]. Hence the program structure of M.Phil. has been designed keeping in mind all of these issues. Ultimately another program namely M.Phil.Big Data and Business Analytics also deal with similar norms of the mode of study, timing, and credit works. Though in this program only the eligibility is different and here following candidates are eligible for the admission.

1. MBA of any UGC recognized University with $50 \%$ Marks

2. M.Com of any UGC recognized University with $50 \%$ Marks

3. M.Sc. of any UGC recognized University with $50 \%$ Marks
Hence in this program eligibility is more flexible and thus it has opened a new vista to other background students as well, mainly M.Com and MBA. Ultimately both the M.Phil. Programs may lead job opportunities in the below mentioned areas/ positions:

1. Data Scientist

2. Business Analyst Consultant

3. Business Analyst Industry Expert

4. Business Analyst Project Manager

5. Data Analyst

6. Data Analyst SAS Programmer

7. Big Data Analyst

8. Data Warehousing Expert

9. Business Intelligence Expert

10. Data Warehousing and BA Architecture

11. Data Mining Expert

12. Cloud Computing Consultants

13. Accelerated Promotions in existing jobs

The course curriculum of the program is depicted in Table II herewith; similar to the previous program it is mainly concentrated on Big Data and Business Analytics. The previous program is concentrated on Big Data and Cloud Computing both while this one is purely dedicated to Data Analytics. Importantly Data Analytics and Big Data are similar in many senses.

TABLE II M.Phil.IN Big Data ANd Business ANALytics Full Structure [20]

\begin{tabular}{|c|c|c|c|}
\hline Sl. No. & Courses & Marks & Study Hours \\
\hline \multicolumn{4}{|c|}{ TRIMESTER 1} \\
\hline 1 & Introduction to Big Data \& Data visualization & 100 & 40 \\
\hline 2 & R - Programming Fundamentals (T\&P) & 100 & 40 \\
\hline 3 & Data warehousing and Data Mining ( $\mathrm{T} \& \mathrm{P}$ ) & 100 & 40 \\
\hline 4 & Big Data Technologies (T \& P) & 100 & 40 \\
\hline 5 & Database Systems in Big Data (T \& P) & 100 & 40 \\
\hline 6 & Optimization \& Predictive Analytics (T \& P) & 100 & 40 \\
\hline \multicolumn{4}{|c|}{ TRIMESTER 2} \\
\hline 1 & Hadoop Distributed File Systems (T \& P) & 100 & 40 \\
\hline 2 & Financial analytics and HR Analytics & 100 & 40 \\
\hline 3 & Big Data \& Multimedia Analytics (T \& P) & 100 & 40 \\
\hline 4 & Data Mining Application with R (T \& P) & 100 & 40 \\
\hline 5 & Text \& Marketing Analytics & 100 & 40 \\
\hline 6 & Digital \& Social Media Analytics / Supply Chain Analytics & 100 & 40 \\
\hline \multicolumn{4}{|c|}{ TRIMESTER 3} \\
\hline \multirow[t]{2}{*}{1} & Project & 600 & - \\
\hline & Total & 1800 & \\
\hline
\end{tabular}

Hence both the programs deals with skill based contents and also industry and research based opportunities. As far as the contact hours is concerned each Trimester is concerned 240 hours of study including lab work. Though combing both the coursework it is 480 Hours except project work or dissertation portion. It is worthy to mention that the institutes offer MSc degree in such fields also bear similar hours for the delivery of the program. These are also standard programs compare to other research focused 2 Year M.Phil. Program in terms of course hours. In general M.Phil. Program normally only 3 Courses are offered while here 12 courses are offered other than project work. 


\section{FUTURE POTENTIALLY: SRINIVAS AND OTHER UNIVERSITY'S CONTEXT}

The Srinivas University already played a significant move in terms of creation of new age programs in the field of IT and Computing. Information Technology primarily deals with the components of Software Technology, Networking Technology, Multimedia Technology, Communication Technology, Database Technology, Web Technology etc. And among these components, most emerging within Networking Technology is Cloud Computing whereas within Database Technology most emerging is Big Data and Analytics. Hence in a country like India where starting a program on components of IT become tough, a move on super specialty based areas as a program worthy in many circumstances. However, this kind of move and initiative can be a great deal for other private universities and also other types of universities viz. Central, State, Deemed etc. Importantly later on other emerging areas and fields may also be started as Academic programs at M.Phil. Level.

1. M.Phil. in Green Computing

2. M.Phil. in Usability Engineering

3. M.Phil. in Human Computer Interaction

4. M.Phil. in Artificial Intelligence

5. M.Phil. in Internet of Things (IoT)

However, later on, it is better to initiate the programs with same curricula as a specialization of the broad domain of Information Technology, Information Science or at-least within Computer Applications.

1. M.Phil. in Information Science/ IT/CA (Green Computing)

2. M.Phil. in Information Science/ IT/CA (Usability Engineering)

3. M.Phil. in Information Science/ IT/CA (Human Computer Interaction)

4. M.Phil. in Information Science/ IT/CA (Artificial Intelligence)

5. M.Phil. in Information Science/ IT/CA (Internet of Things)

Though in India, most common branches in IT and Computing are Computer Science, Computer Application, and Information Technology. And other branches of Information Science, Information Systems are still very limited and not available. Hence at this stage, the branch of Computer Application may be a suitable alternative regarding the specialized M.Phil. Program.

\section{CONCLUSION}

The computer is most important tool these days and as far as Information Technology is concerned it is a valuable component for the development of every kind. Information Technology and its application are limitless. Many universities worldwide are doing the research work for the betterment of societies. Research Degrees viz. M.Phil., PhD, DSc, M.Tech. (Research) etc. have their role in the development of different perspective. Initially, only research work as the form of thesis and dissertation was considered as most important and valuable. But gradually such degrees especially in M.Phil. and PhD, coursework is considered as most important and valuable. Initially, only research methodology related papers and techniques (such as Computer Applications) considered as vital for the said degree. But later on, the coursework with other areas of research and skill sets becomes valuable in many universities in the world. For example candidates of Computer Science when pursuing Research Degrees in Networking Technologies, only Topic based research and submission of the thesis was vital but gradually many universities started Network Technology related courses during their Research Degrees as well. Hence in this way very few universities in India also started research degrees with coursework in the areas of interest/work and in this case Srinivas University played a vital role. And in this segment, other universities are essential to involve for the creation of candidates having the knowledge to work in the industry and research related affairs as well.

\section{REFERENCES}

[1] J. B. Tilak and, N. V. Varghese, "Financing higher education in India”, Higher Education, vol. 21, No. 1, pp. 83-101, 1991.

[2] P. G. Altbach,, "The dilemma of change in Indian higher education”. Higher Education, Vol. 26, No. 1, pp. 3-20, 1993.

[3] I. Dayal, "Developing management education in India”, Journal of management Research, Vol. 2, No. 2, pp. 98-113, 2002.

[4] P. G. Altbach, "Globalisation and the university: Myths and realities in an unequal world”, Tertiary Education and Management, Vol. 10, No. 1, pp. 3-25, 2004.

[5] P. Agarwal, "Higher education in India: Growth, concerns and change agenda”, Higher Education Quarterly, Vol. 61, No. 2, pp. 197-207, 2007.

[6] V. Umashankar and K. Dutta, "Balanced scorecards in managing higher education institutions: an Indian perspective”, International Journal of Educational Management, Vol. 21, No.1, pp. 54-67, 2007.

[7] I. Bhattacharya and K. Sharma,, "India in the knowledge economy-an electronic paradigm”, International Journal of Educational Management, Vol. 21, No. 6, pp. 543-568, 2007.

[8] S. Jalaluddin Haider, and K. Mahmood, "M.Phil.and PhD library and information science research in Pakistan: An evaluation”, Library Review, Vol. 56, No. 5, pp. 407-417, 2007.

[9] J. B. Tilak, "Transition from higher education as a public good to higher education as a private good: The saga of Indian experience”, Journal of Asian Public Policy, Vol. 1, No. 2, pp. 220234, 2008.

[10] K. Garg and V. Varma, "Software engineering education in India: Issues and challenges”, In Software Engineering Education and Training, 2008. CSEET'08. IEEE 21st Conference on IEEE, pp. 110117 , April 2008.

[11] G. Gereffi, V. Wadhwa, B. Rissing and R. Ong, "Getting the numbers right: International engineering education in the United States, China, and India”. Journal of Engineering Education, Vol. 97, No.1, pp. 1325, 2008.

[12] S. Desai and V. Kulkarni, "Changing educational inequalities in India in the context of affirmative action”, Demography, Vol. 45, No. 2, pp. 245-270, 2008.

[13] S. C. Basak and D. Sathyanarayana, "Pharmacy education in India”, American journal of pharmaceutical education, Vol. 74, No. 4, pp. 68, 1-8, 2010.

[14] S. K. Mitra "Internationalization of education in India: Emerging trends and strategies”, Asian Social Science, Vol.6 No. 6, pp. 105110, 2010. 
[15] D. Gupta and N. Gupta, "Higher education in India: structure, statistics and challenges”, Journal of education and Practice, Vol. 3, No. 2, pp. 17-24, 2012.

[16] P. K.. Paul, A. Kumar, E. Poovammal and K. L. Dangwal, "Information Science: A Potential interdisciplinary field with Historical Perspectives and Future Potentials”, Educational Quest, Vol. 5, No. 3, pp. 211-216, 2014.

[17] P. K. Paul, P. S. Aithal and A. Bhuimali, "Computing and Allied Engineering Domain in India with Reference to Private Universities: A Case Study of Bachelors Programs”, International Journal on Recent Researches In Science, Engineering and Technology, Vol. 5, No. 11, pp. 51-63, 2017.
[18] P.K. Paul, P. S. Aithal and A. Bhuimali, "MCA (Information Science and Management): The next Generation Interdisciplinary Specialization for Better Social Informatics and Digital Humanities Practice", International Journal of Scientific Research in Mathematical and Statistical Sciences, Vol. 4, No. 5, pp. 27-32, 2017.

[19] http://srinivasuniversity.edu.in/college-of-computer-informationsciences/postgraduate-programmes/m-phil-in-data-analytics-cloudcomputing/

[20] http://srinivasuniversity.edu.in/colleges-of-business-managementcommerce/postgraduate-programmes/m-phil-in-big-data-businessanalytics/ 